\title{
A REVIEW OF RECENT PAPERS ON ONLINE DISCUSSION IN TEACHING AND LEARNING IN HIGHER EDUCATION
}

\author{
Michael Hammond \\ Centre for New Technologies Research in Education \\ Institute of Education \\ University of Warwick
}

\begin{abstract}
This paper presents a review of a sample of recent case studies on the use of asynchronous online discussion in higher education. These studies are analyzed in terms of curriculum design, assumptions about teaching and learning, and claims and reported conditions for using online discussion. The claims made for asynchronous online discussion - in particular the opportunities for interaction between learners, and permanent access to these interactions-are found to be frequently based on social constructivist principles. Asynchronous online discussion is seen as offering additional value by providing learners with experience of computer communication tools and opportunities for taking part in group work. Several constraints on participation within online forums are described. These are discussed in relation to the nature of curriculum design, software design, tutor support, and learners' attitudes and previous experience. The conditions under which asynchronous online discussion may best support learning are set out, and avenues for future research are suggested.
\end{abstract}

\section{KEYWORDS}

Asynchronous Discussion, Literature Review, Case Studies

\section{INTRODUCTION}

The theme of this paper is teaching and learning through asynchronous online discussion in higher education. The paper reports on case studies in which email lists or conferencing programs such as First Class and WebBoard have been used to support learners who are registered with a higher education institution and, in most cases, following an accredited course. Asynchronous online discussion is used as a catchall to include such widely used terms as computer-mediated communication and threaded discussion and to cover approaches such as cooperative computer-supported learning, collaborative computersupported learning, and online group work.

Several reviews of the literature on asynchronous online discussion have already been published. Wallace [1] has provided a thorough review focused on the notions of transactional distance, interaction, and social presence. In a similar vein, Zhao and Rop [2] carried out a review of forums for teachers. Many of the forums fell outside the scope of the Wallace paper, but interestingly the authors make a point similar to Wallace's: research needs to be more explicit in addressing learning gains associated with online discussion. A number of the case studies reviewed for this paper contain thorough overviews of existing literature, e.g., Anderson et al. [3] on the tutoring role, Aviv [4] on the social construction of knowledge, Brown [5] on conditions for learning, and van Weert and Pilot [6] on curriculum design. Why then another paper? The aim is to undertake a systematic review of a tightly sampled section of the literature to 
contribute to a more detailed picture of the part played by asynchronous online discussion in higher education and to specifically report on models of curriculum design, theoretical perspectives on teaching and learning, evidence that supports the use of asynchronous online discussion, and conditions under which learners are most likely to participate.

\section{A. Sample and Selection Criteria}

Seven international journals were selected to provide a perspective on developments in asynchronous online discussion, particularly those based in the UK and US. Six of these journals are widely seen as the most influential in the UK information and communications technology (ICT) research community; the seventh, Journal of Asynchronous Learning Networks, was chosen because of its specialist concern with asynchronous networks and its greater coverage of initiatives in North America. The range was broad enough to enable worthwhile generalizations, but many other frequently-cited journals, such as Internet and Higher Education, Journal of Computer-Mediated Communication, and Australasian Journal of Educational Technology, could also have been included. It is hoped that this paper will stimulate further reviews using a more internationally mixed range of publications; however, the literature has become so extensive that a fully inclusive survey is impossible. The following criteria were used to identify relevant papers within the seven journals:

- Case studies, usually a case study of a particular course, although Anderson et al. [3] report on more than one course in the same paper. However, papers that conflated the findings of several case studies, or were empirical studies in which students attended different courses, were not included because they tended not to provide details of curriculum design.

- Based in higher education institutions and organized by academic staff.

- Focused on asynchronous online discussion, although in many cases online discussion ran alongside other learning events (such as face-to-face meetings) or other learning materials (such as web resources and online lectures).

- Focused directly on teaching and learning - for example, papers that focused on implications for the institutions or predominantly on methods for content analysis were not included.

- Published between 2000 and 2004; this was to provide an up-to-date view of the field with a consistent cutoff point.

Sixty-two papers met these criteria. Twenty papers appeared in the Journal of Asynchronous Learning Networks: Anderson et al. [3], Aviv [4], Aviv et al. [7], Biesenbach-Lucas [8], Brown [5], Campos [9], Curtis and Lawson [10], Graddy [11], Koory [12], Kumari [13], Meyer [14], Morse [15], Oliver and Shaw [16], Parker and Gemino [17], Picciano [18], Ross et al. [19], Shaw and Pieter [20], Spiceland and Hawkins [21], Vandergrift [22], and Yang and Tang [23]. Nine papers were published in the British Journal of Educational Technology: Angeli, Valanides, and Bonk [24], Carswell et al. [25], Collings and Pearce [26], Cunningham-Atkins et al. [27], Lindblom-Ylänne and Pihlajamäki [28], Macdonald and Twining [29], Murphy [30], Salmon [31], and Wearmouth et al. [32]. Nine appeared in Computers and Education: Hubscher-Younger and Narayanan [33], Johnson et al. [34], Kear [35], Light et al. [36], MacDonald [37], Martinez et al. [38], Mazzolini and Maddison [39], Tolmie and Boyle [40], and Wilson [41]. Two were published in Education, Communication and Information: Putz and Arnold [42] and Swan [43]. Six appeared in Education and Information Technologies: De Abreu Moreira and Quintino Da Silva [44], Hawkey [45], Hawkey [46], Lockhorst et al. [47], van Weert and Pilot [6], and White and Le Cornu [48]. Six were published in the Journal of Computer-Assisted Learning: Chen, Wang, and Ou [49], Jones and Asensio [50], De Laat and Lally [51], Ritchie and Peters [52], Thomas [53], and Weller [54]. Finally, ten papers appeared in Technology, Pedagogy and Education: Åhlberg et al. [55], Brett [56], Clarke [57], Cook and Ralston [58], Galanouli and Collins [59], Mackinnon [60], Maor [61], Miller and Ewing [62], Seabrooks et al. [63], and Tsui and Ki [64]. 
Each paper was categorized by journal, discipline area, country in which study took place, and software used. Although still heavily weighted towards North American and UK-based initiatives within teacher education, the sample papers covered different subject areas (Table 1) and were based in different countries (Table 2). A wide range of software was used in the studies; there are specific references to twenty-one separate programs, with First Class, mentioned in eleven papers, the most frequently cited.

\begin{tabular}{|c|c|c|c|}
\hline Context & Frequency & Context & Frequency \\
\hline Initial teacher education & 15 & Health and medicine & 4 \\
\hline Computing & 12 & English literature & 2 \\
\hline Education & 11 & Psychology & 2 \\
\hline Business and economics & 5 & Astronomy & 1 \\
\hline $\begin{array}{c}\text { Educational technology } \\
\text { Human resource development and } \\
\text { management }\end{array}$ & 5 & Law & 1 \\
\hline
\end{tabular}

Table 1: Frequency with which Papers Reported on Different Subject Disciplines (n = 63; Anderson et al. [3] report on two different discipline areas)

\begin{tabular}{|c|c|c|c|}
\hline Location & Frequency & Location & Frequency \\
\hline UK & 19 & New Zealand & 2 \\
\hline US & 17 & Taiwan & 1 \\
\hline Australia & 7 & Austria & 1 \\
\hline Canada & 5 & Hrazil & 1 \\
\hline Finland & 2 & Ireland & 1 \\
\hline Holland & 2 & & \\
\hline
\end{tabular}

Table 2: Countries in which the Forums in the Case Studies were Located (n=62)

\section{B. Themes and Focus Questions}

Once the nature of the sample was established, the papers were then further categorized by theme. Examples of focus questions associated with each of these themes are given below, along with an example of the notes taken on a particular paper.

\section{Curriculum Design}

What is the role of asynchronous online discussion in the course design? How is discussion structured (e.g., group-based tasks, open discussion, formal seminar format)? What is the role of the instructor? How are contributions assessed? What content is accessed? Is there an explicit curriculum model? For example, Putz and Arnold [42] discuss a seminar format: twelve learners organized into smaller groups to critically review papers. The paper describes a loose structure, albeit with specific deadlines for introduction and reflections. The instructor and invited guests support but do not direct groups, and the format includes extensive formative feedback on contributions and an end-of-unit assessment.

\section{Theoretical Assumptions About Teaching and Learning}

Which theories of teaching and learning underpin the work (e.g., community of practice, social constructivism)? For example, Aviv [4] sees the social interdependence theory of learning as a key point of reference, and research questions emerge from his extensive review of the literature. 


\section{Claims Made for Asynchronous Online Discussion within the Case Study}

How, if at all, do forums support learning? How strong are the claims? What are the key reported benefits? For example, Vandergrift [22] describes a learning community and suggests dramatic gains in personal learning result from taking part in discussion; the background and willingness of students to communicate, rather than online forums per se, are seen as central to success. The study is exploratory, raising questions for further investigation.

\section{Conditions}

What are the key conditions under which asynchronous online discussion contributes to student learning? What are the reported constraints on learners? For example, Hawkey [45] highlights structure and direction as important and sees scope for peer review in assessment and evaluation. The paper recognizes that the medium is challenging for some students because text is public and permanent. Teachers need to help students understand the nature of the medium.

Comments made within each category were then analyzed, with key themes identified and described below.

\section{RESULTS}

\section{A. Curriculum Design}

Difficulties arose in categorizing curriculum design because the exact nature of the activities with which learners were expected to engage, the role of assessment, and the relationship of asynchronous online discussion to other parts of the course experience were not spelled out in all papers. Some writers offered explicit curriculum models, e.g., Vandergrift [22] and van Weert and Pilot [6], but many did not. Nonetheless, three types of online discussion activity were identifiable.

- Open forums in which participants were free to contribute as and when they liked and in which the agenda for discussion was only loosely guided, e.g., Carswell et al. [25], Cook and Ralston [58], Galanouli and Collins [59], Maor [60], Miller and Ewing [62], Shaw and Pieter [20], Tsui and Ki [64], and Weller [54]. Discussion appears to have been sustained through moderator input (Galanouli and Collins [59] is an exception); the rotation of the role of group moderator (e.g., Maor [60]); selecting volunteer participants to take part in a trial (e.g., Weller [54]); and, in Tsui and $\mathrm{Ki}$ [64], a requirement to post a message at least twice a month to stay registered on the forum. Carswell et al. [25], Cook and Ralston [58], and Tsui and Ki [64] describe large forums generating a substantial number of messages even if some members participated infrequently. Participation in the conference was not assessed.

- Loosely structured forums in which learners were expected to complete certain tasks on an individual basis and post task results for group discussion. For example, in Angeli et al. [24] learners were required to post a case arising from their teaching placement, and their participation rather than their performance was assessed. In Collings and Pearce [26], learners were expected to produce a web site for peer evaluation and comment on those produced by their peers. Several studies described online seminars based around specific readings and events. Hawkey [45] described a loosely structured forum for trainee teachers based on the experience of a shared school visit and linked to preparation of a course assignment. This approach was followed up in a study (Hawkey [46]) of a more directed approach requiring trainee teachers to comment on each other's work. Putz and Arnold [42] and Kumari [13] provided a structure for discussion by using guest experts as participants within online seminars. In Morse [15], learners were provided with 
A Review of Recent Papers on Online Discussion in Teaching and Learning in Higher Education

specific readings on which to comment. In these loosely structured forums, summative assessment of participation was uncommon, but Oliver [16] described a case study in which learners were given course credits for participation.

- Cooperative or collaborative task-based forums in which learners were expected to work in small teams in order to complete an assignment (e.g., Lockhorst et al. [47] and Kear [35]) with formative and often summative assessment built into online activity. Several of these studies were centered upon case-based inquiry. For example, in Martinez et al. [38] pairs of learners proposed a best fit solution for a computer system in a simulated commercial setting, and in Yang and Tang [23] learners worked in teams (usually three people) to prepare a case study on the implementation of a management information system. This approach required groups to set focus questions for other learners and respond to cases set by other teams. Peer review was undertaken in several studies, e.g., in De Abreu Moreira and Quintino Da Silva [44] discussed a focus on giving feedback on the web sites other learners had designed, and Aviv et al. [7] described and contrasted two approaches, one relatively open and one highly structured. In Jones and Asensio [50] and Aviv et al. [7] group work tasks were interspersed with more independent activity.

\section{B. Theoretical Assumptions about Teaching and Learning}

Most papers began with an introduction to the growing importance of online learning in education and highlighted the importance of interaction between learners as the most important contribution of online forums to learning. In the majority of papers, interactivity was linked to a theory of teaching and learning with which the authors wished to align themselves, or at least hypotheses about teaching and learning that they wanted to investigate. Hiltz et al. [64] have made the point that research into the asynchronous online discussion may be situated within three fields: educational research, media analysis, and social psychology, and these are considered below. Definitions of these three fields are contested, but for the purposes of this paper, it can be said that they, respectively, differentiate between a focus on teaching and learning; concern the impact of the media on individuals and groups; and study the behavior of the individual within a group.

\section{Educational Research}

Not surprisingly, the major point of reference within the sampled literature was education theory and that of social constructivism in particular, e.g., Collings and Pearce [26], Hawkey [45], Kear [35], LindblomYlänne and Pihlajamäki [28], Macdonald and Twining [29], Mackinnon [60], and Maor [60]. The term social constructivism was used in a broad way and implied social interaction and active "meaning making" by learners (e.g., Yang and Tang [23] and Angeli et al. [24]) often derived from principles developed by Vygotsky [65]. MacDonald and Twining [29] usefully saw social constructivism as a catchall term to which related concepts such as cooperative and collaborative group work, transactional distance, and community of practice - all of which regularly appeared in the literature-belonged. A less frequently recurring concept was that of conversational learning, based on references to Laurillard [66]. Thomas [53], for example, used this term to highlight the importance of both internal and interactive dialogue within online learning environments, and Kumari [13] discussed the conversational nature of learning in more general terms.

The terms cooperative and collaborative were not always used consistently within the papers, but they did signpost varying levels of collaboration and structure. For example, Curtis and Lawson [10], citing earlier authors, made a distinction between cooperative and collaborative learning. Cooperative learning involves the completion of a task by breaking it down into subtasks that team members solve independently, whereas collaborative learning involves team members working together to develop a joint solution to a 
problem. Collaborative learning suggests a higher order of interaction, although this was not a distinction universally followed. Aviv et al. [7], for example, investigated the regulation of high-level reasoning within a study of cooperative learning, citing, like many other authors, the work of Johnson and Johnson [67] in which the term cooperative learning described a higher order collaborative process. Murphy [30] saw collaboration as a continuum involving progression along six processes ranging from acknowledging social presence to producing shared artifacts.

Many papers looked at the notion of community and learning within a community of practice, e.g., Vandergrift [22], Brown [5], Putz and Arnold [42], Tsui and Ki [64], and van Weert and Pilot [6]. These terms were generally used to imply the presence of both reflective and reflexive discussion within the community. Putz [42] argued that a community of practice needed to be small enough for learners to be acquainted, to share an understanding of purpose and conduct, and to facilitate entry of new members to the group; he described five design dimensions that needed to operate within an online learning community. Clarke [57] drew on Lave and Wenger [68] to describe a community of practice as one in which learners evolve forms of mutual engagement; understand and "tune" their enterprise; and develop a repertoire, style, and discourse. Meanwhile, Anderson et al. [3] described a community of inquiry model with three elements: cognitive presence, teaching presence, and social presence; the paper in the sample reported on teaching presence.

Often linked to ideas of community of practice were those of problem-based learning and team-based cooperative learning. For example, van Weert and Pilot [6] discussed three principles in online innovation: task-based learning within authentic or realistic learning situations, team learning, and the use of groupware. This approach was informed not only by the social and cognitive value of working with others but also by the need to provide a more authentic and more relevant professional preparation.

Among the less frequently used learning theory concepts were transactional distance-for example, Vandergrift [22] used the term to draw attention to the communication gap between teacher and learners when separated by space and time. Others included reflective practice, Salmon [31]; narratives in learning, Ritchie and Peters [52]; mentoring, Seabrooks et al. [63]; and adult learning, Koory [12].

\section{Media Theory}

Few papers used media theory as a starting point. However, the attributes of conferencing systems-in particular the importance of affording permanent storage of text-based interactions, accessible anytime and from anywhere-were frequently discussed. This theme was often followed up with reference to the absence of visual clues within messages. However, the examination of media rarely went further, and little material was available on the process of text composition or the comparison of, for instance, asynchronous to synchronous approaches or the affordances of text as against image. There were few detailed discussions of the merits of particular software within the literature, although a paper by Ross et al. [19] was an exception in presenting an analysis of instructors' and learners' priorities and behavior in accessing and organizing mailings within First Class conferencing software.

\section{Social Psychology}

Few papers adopted social psychology as an explicit starting point, except in the obvious sense that social psychology is a broad enough concept to take in educational theory. Distinctive social psychological perspectives became more obvious in discussions of social presence (e.g., Anderson et al. [3]) and more so when social network analysis (SNA) was introduced (e.g., Aviv et al. [7], Lockhorst et al. [47], and Chen et al. [49]). Aviv et al. [7] defined SNA as a graphical analysis of actors within a network based on 
A Review of Recent Papers on Online Discussion in Teaching and Learning in Higher Education

characteristics of cohesion, role groups, power of actors, range of influence, and brokerage. SNA, it was argued, can be used to reveal the structure of networked learning and provide evidence for its effectiveness.

Biesenbach-Lucas [8] and Morse [15], in particular, took up the cultural dimension of asynchronous online discussion. Biesenbach-Lucas [8] looked at perceptions of native and non-native trainee teachers, and Morse [15] explored the feedback of learners with preferences for low- and high-context learning. Learning styles were discussed in several papers, and Carswell et al. [25] used the Honey and Mumford learning styles inventory (activists, reflectors, theorists, and pragmatists) as a reference point for discussing different responses within forums.

\section{Claims Made for Asynchronous Online Discussion within the Case Studies}

Most papers were measured in their support for the use of asynchronous online discussion and highlighted the constraints on learners as well as the opportunities that asynchronous online discussion offered. Most stressed that they were reporting exploratory work in which lessons had been learned and that alternative approaches might be more successful in the future. The focus was often on improving curriculum design or instructor practice rather than establishing the value of asynchronous online discussion per se. Almost all papers had an action research element to them-although action research was not referred to explicitly-and there seemed to be an initial optimism about the use of asynchronous online discussion that had led researchers to undertake innovations in their teaching. Few authors were prepared to make a statistical comparison between online and face-to-face discussion or to argue that online interaction was inherently better than face-to-face. However, the majority concluded that asynchronous online discussion was potentially valuable or very valuable as a support for teaching. Three general arguments were used as evidence:

- Asynchronous online discussion provided opportunities for interaction between learners that contrasted with noninteractive, traditional, or transmission models of teaching. In many cases, papers reported on interaction that could not otherwise easily take place because learners were at a distance from one another.

- Many papers reported on relatively high rates of participation and evidence of learner presence and interactive learning styles. Many claimed that students had appreciated the use of asynchronous online discussion.

- Many reported on learners' appreciation of social support and found this a motivation to study.

In addition, several papers cited more specific sources of evidence:

- The presence of higher order discussions and knowledge building within forums, e.g., Åhlberg et al. [55], Aviv et al. [7], Curtis and Lawson [10], Thomas [53], and Campos [9], although each paper contained some qualifications on the extent to which the construction of new knowledge was achieved. In addition, Brown [5], Clarke [57], Putz and Arnold [42], and Vandergrift [22] argued that the presence of a community of learners and the development of an online community was both possible and desirable.

- The permanent storage of messages providing support for reflection, e.g., Salmon [31], and expansion of available time for learning, e.g., Macdonald and Twining [29] and Meyer [14].

- Access to virtual guests to widen the experience of learners, e.g., Kumari [13] and Wearmouth [32].

- The flexibility of the medium, e.g., Biesenbach-Lucas [8], Light et al. [36], and Hawkey [46], and the opportunity to create an environment to meet student and instructor needs.

- Added value to the learners' experience. Here a general theme was the development of ICT skills and greater understanding of the contribution ICT can make to learning, e.g., Galanouli and 
Collins [59]. Other writers drew attention to gains in self-confidence through the carrying out of group activities, e.g., Miller and Ewing [62] and Tsui and Ki [64]. Lindblom-Ylänne and Pihlajamäki [28] saw added value in using the medium of text to discuss essay writing; likewise, Koory [12] saw the medium as especially pertinent to a literature class.

- The relevance of online activity for professional learning. For example, Collings and Pearce [26] described how online discussion enables trainee web designers to carry out usability trials of web sites, and van Weert and Pilot [6] saw group-based discussion as intrinsic to professional preparation.

\section{Optimal Conditions for Asynchronous Online Discussion}

Most papers highlighted constraints on learners, and nearly all papers drew attention to a range of issues that affected the impact of online discussion. These issues were apparent in skewed rates of participation and lack of evidence of interaction between writers of messages. Conditions for taking up asynchronous online discussion were described in reference to a set of interrelated issues in curriculum design, teaching, software (including access and choices of programs), and learners’ behavior and attitudes.

\section{Curriculum Design Issues}

Curriculum design was the most frequently discussed condition for group cohesion and participant engagement. Major issues here were structure, assessment, and fitness for purpose. Several writers, notably Aviv et al. [7], argued that a structured curriculum would lead to more cohesion. The implication was that learning activities should be timetabled, roles and responsibilities made explicit, and further structure might be provided by timetabling guest experts. A number of researchers found that curriculum designers needed to build in opportunities for reflection, and Salmon [31] and Koory [12] looked for curriculum design to address adult learning styles. Several papers reported on the importance of not overloading learners and advised curriculum designers to recognize the demands made on learners within an online environment, e.g., Meyer [14] and Collings and Pearce [26].

Formative peer assessment was an expected outcome of many of the forums discussed in the literature, and several writers went on to discuss the role of summative assessment. For example, Biesenbach-Lucas [8] found that learners tended to summarize rather than analyze in their online contributions, and suggested that assessment of participation might provide learners with the motivation to become more critical. MacDonald [37] and Macdonald and Twining [29] stressed the importance of assessing learners' contributions to the group work process, not just group products. However, Oliver [16] argued that assessing contributions might increase the number of postings but not necessarily learner engagement.

Several papers suggested that some contexts were more suitable than others for asynchronous online discussion. Group-based learning needed to be integral to course design, and Parker and Gemino [17] argued that online discussion offered better support for conceptual learning than acquisition of skills or techniques. Putz and Arnold [42] suggested that online discussion was less likely to be of value if face-toface meetings were easy to organize.

\section{Instructor Support}

Discussion of curriculum design overlapped with discussion of instructor support in many practitioner accounts of how asynchronous online discussion was introduced. However, some papers, e.g., Anderson et al. [3], De Abreu Moreira and Quintino Da Silva [44], Hawkey [45], Miller and Ewing [62], Salmon [31], and Oliver and Shaw [16], had a specific focus on instructor presence. Anderson et al. [3] made a 
A Review of Recent Papers on Online Discussion in Teaching and Learning in Higher Education

distinction between teacher presence and teaching presence but still recognized the special contribution of the course instructor even if other learners might take on quasi-teaching roles. Left to themselves, learners might be reluctant to disagree, challenge, or even respond to others in the group, and Galanouli and Collins [59] were alone in their sympathy for teacherless groups. Other writers believed that instructors needed to signal their presence and to provide administrative, pedagogic, and affective or pastoral support. Teachers needed to encourage divergence within the group, suggest roles, and introduce "starter" and "wrapper" activities. Mackinnon [60] and Chen et al. [49] suggested that teachers need ways of recording and analyzing discussion and provided tools for helping them do so.

Light et al. [36] noted that teachers would inevitably draw on face-to-face teaching styles when teaching online, but the transition to online instructor was not straightforward. Both Anderson et al. [3] and Salmon [31] argued that teachers needed to develop strategies to compensate for the lack of nonverbal and paralinguistic cues. Difficulties in the role of teacher were discussed. Hawkey [45], for example, saw the need for direction if student interaction was to develop beyond an exchange of information, but this approach posed a dilemma for an instructor wanting learners to take responsibility for their own learning, and Maor [61] drew attention to the dual role of teacher as both co-learner and coordinator.

\section{Learners' Behavior and Attitudes}

Comparatively few papers looked at the attributes and responsibilities of learners within asynchronous online discussion. Learners were seen as needing some proficiency in using ICT, and of course access to ICT, but experience and understanding of group work were more important factors in explaining patterns of learner participation. Several researchers, most notably Brett [56], Carswell et al. [25], Galanouli and Collins [59], Lindblom-Ylänne and Pihlajamäki [28], Meyer [14], Tsui and Ki [64], and Wilson [41], discussed learning styles and their influence on participation and attitudes. A learner's willingness to engage with other learners was seen as related to preferred learning style, confidence and self-esteem, cultural background, and linguistic ability. For example, Morse suggested that high-context learners may be disadvantaged within online forums along with those for whom English (as in his study) was an additional language or those who lacked fluency in writing English. Meyer [14] felt that auditory learners would prefer and take fuller part in face-to-face settings, whereas Wilson [41] suggested that intuitive learners might not take as easily to text-based environments as reflective learners. Cunningham-Atkins et al. [27] found some evidence that imagers sent more messages, but the authors maintained that having a mix of learning styles within a group was important. Lindblom-Ylänne and Pihlajamäki [28], Tsui and Ki [64], and Wearmouth [32] noted that learners needed to be self-confident if they were to make public and permanent contributions in forums; some would find this kind of disclosure too threatening, although others boosted their self-esteem once overcoming initial inhibitions. Brett [56] saw an association between a learner's level of activity and his or her confidence with the subject matter at hand and found that levels of activity tended to vary little over an extended period of time. Graddy [11] explored the influence of gender hierarchy and argued that moderators had a role in identifying and addressing genderbased impediments. Finding a different angle on participation, Galanouli and Collins [59] sought to understand online activity in terms of the information gap between learners and their willingness to cross it, rather than in terms of learning style or other individual characteristics.

\section{Software}

As described earlier, discussion of technology was largely focused on the permanent storage of threaded discussion rather than the characteristics of particular programs. However, Thomas [53] looked at the medium more critically and wondered if text-based communication was appropriate for many types of learning because it lent itself to transactional rather than interactive exchange. Many papers, notably Shaw and Pieter [20], did comment generally on the need for reliable access and user-friendly tools, and 
several commented on the benefits of discussion forums over email lists. Ahlberg et al. [55] saw valuable design features in knowledge forum software, and Kear [35] argued that threading systems needed to provide users with a clear visual representation of messages. Lindblom-Ylänne and Pihlajamäki [28] found that learners had difficulties sending attachments in their study-again, the software needed to be intuitive to use. Ross et al. [19] argued that instructors needed greater awareness of the patterns or routines learners developed when accessing forums.

\section{CONCLUSION}

These papers give useful insight into the nature of and the claims made for asynchronous online discussion, as well as the conditions under which learners are more likely to engage with each other. Researchers express broad agreement that the argument for using asynchronous online discussion rests in a commitment to interaction between learners and adherence to a social constructivist approach to teaching and learning. Interactivity is seen as enabled by the permanent storage of text, accessible anytime from anywhere. The literature looks at the implications for teaching and learning and largely rejects a technological determinism or technological romanticism. Most of the research avoids linking the use of the technology to easily quantifiable learning gains; most instead describes technology's contribution to teaching and learning. Thus, researchers often report on learners' perception of benefits and drawbacks in using asynchronous online discussion, and it not surprising that these perceptions are difficult to describe and measure. These papers tend to avoid asking whether asynchronous online discussion is a good thing and instead try to identify the difficulties in getting started and the ways in which discussion can best be conducted to support learning.

\section{A. Broad Consensus on Best Practices}

Although most of the reported research is encouraging about the use of asynchronous online discussion, researchers agree that learner participation is not assured. The literature tends to focus on curriculum design and instructor support as key elements in promoting learner engagement and to treat software design as much less important. None of the papers claim that participation is in itself sufficient to ensure that learning takes place, but all recognize that low levels of interaction and low evidence of higher order thinking in message analysis negates the arguments for using asynchronous online discussion in the first place. A broad, but not complete, consensus on the conditions under which learners will best engage with asynchronous online discussion is presented below:

- Curriculum designers should encourage formative peer assessment; provide summative assessment of process and credit for participation; provide summative assessment of group products; make group work and problem-based learning explicit in learning outcomes; require a minimum level of participation; set explicit tasks (e.g., discussion of cases, readings, or shared events); build in review of group work process; adjust workload to allow time for discussion; make conceptual learning and higher order reasoning explicit and appropriate learning outcomes; build in appearances of online guests; and rotate roles within the group.

- Instructors should draw on past experience but appreciate the unique features of the online environment; show teaching presence but encourage critique and divergence; fade as appropriate; have an administrative role (e.g., notify students of assessment arrangements); have a pastoral role (e.g., identify and support nonparticipants); be aware of their pedagogic role (e.g., respond where appropriate); suggest activities and roles to generate debate; and take responsibility for monitoring the nature and scope of discussion and group processes.

- Learners should have knowledge, experience, and understanding of the benefits of group work; be confident in and have some level of proficiency in ICT; have access to ICT; not be able to 
easily meet face-to-face; be ready to critique the authority of the tutor; find that text-based communication suits preferred learning style; have proactively chosen to take part; be confident in contributing to public forums and ready to constructively critique other points of view; be proficient in language of the forum and fluent writers; and be aware of an information gap and eager to cross it.

- Software should allow permanent storage and threading of messages; be robust and provide reliable access to messages; be intuitive, easy to use, and offer good visual representation; and enable files to be easily attached and downloaded.

From this perspective, asynchronous online discussion would seem to offer most to collaboratively minded learners comfortable with ICT and studying a topic requiring conceptual understanding. These learners need to be supported by an experienced instructor aware of his or her responsibilities and roles. Asynchronous online discussion would seem to have least to offer independent-minded learners who meet face to face. Participation is even less likely if these learners lack teacher support and are aiming to acquire essentially practical, non-ICT-related skills.

\section{B. Directions for Future Research}

The strengths of the papers discussed in this review lie in their exploratory nature, their focus on teaching and learning, and their pragmatic consideration of opportunities for and constraints on learners. However, several areas remain to be addressed by future case studies. Four of the most pressing are described below.

First, the need to develop curriculum models. Although the research thoroughly engages with broad theories of learning such as constructivism and communities of practice, few papers succeed in developing applied models of teaching-indeed, in several papers it was unclear what precisely the learners were expected to do within the forums to which they belonged. Modeling would enable easier comparison between studies and better tracking of learning outcomes to specific online activity.

Second, to clarify and take a more critical stance towards interaction between learners. Many commentators take a strategic view of interactivity; it is often assumed that interaction assists learning, and the more interaction, the more successful the learning outcomes. Several papers try to measure learning outcomes associated with participation in forums, although singling out one variable within a complex teaching and learning event is hard to defend methodologically, and results are capable of varied interpretation. In contrast, few papers make the case for interaction between learners as an educational value in its own right, and there is almost no critical comment on the limits of interaction or appreciation of those who prefer not to participate.

Third, the transferability of approaches to other settings. Many of the case studies are set in the context of initial teacher education, arguably a consequence of the imposition of ICT standards in teacher education in both the US and UK. The next most frequently occurring context is that of computing, in which learners again are likely to have an intrinsic interest in or requirement to explore the process of online collaboration. However, few papers directly address transferability from these to other contexts, particularly ones in which learners may have little interest in the process of online learning per se.

Fourth, more awareness of the limits on course designers and instructors when trying to generate discussion. Teachers are asked to identify, monitor, and address learning styles, gender imbalances, 
organization of material, access issues, and assessment, and they carry a general responsibility for affective, administrative, and pedagogical support. The teacher role is a demanding one, in particular in a context in which the teacher has less control than in a face-to-face setting, not least because learners can easily and unobtrusively withdraw their presence. Many papers seem reluctant to critically address the responsibility of learners to participate, the characteristics of the learners to whom online discussion would most or least appeal, and, above all, the nature of the information gap that learners are being asked to bridge.

\section{REFERENCES}

1. Wallace, R. Online learning in higher education: A review of research on interactions among teachers and students. Education, Communication and Information 3(2): 241-280, 2003.

2. Zhao, Y. and S. Rop. A critical review of the literature on electronic networks as reflective discourse communities for in-service teachers. Education and Information Technologies 6(1): 81-94, 2001.

3. Anderson, T., L. Rourke, R. Garrison, and W. Archer. Assessing teacher presence in a computer conferencing context. Journal of Asynchronous Learning Networks 5(2): 1-17, 2001.

4. Aviv, R. Educational performance of ALN via content analysis. Journal of Asynchronous Learning Networks 4(2): 53-72, 2000.

5. Brown, R. The process of community-building in distance learning classes. Journal of Asynchronous Learning Networks 5(2): 18-35, 2001.

6. van Weert, T. and A. Pilot. Task-based team learning with ICT: Design and development of new learning. Education and Information Technologies 8(2): 195-214, 2003.

7. Aviv, R. Z. Erlich, G. Ravid, A. Geva. Network analysis of knowledge construction in asynchronous learning networks. Journal of Asynchronous Learning Networks 7(3): 1- 23, 2003.

8. Biesenbach-Lucas, S. Asynchronous discussion groups in teacher training classes: Perceptions of native and non-native students. Journal of Asynchronous Learning Networks 7(3): 24-46, 2003.

9. Campos, M. A constructivist method for the analysis of networked cognitive communication and the assessment of collaborative learning and knowledge-building. Journal of Asynchronous Learning Networks 8(2): 1-29, 2004.

10. Curtis, D. and M. Lawson. Exploring collaborative online learning. Journal of Asynchronous Learning Networks 5(1): 21-34, 2001.

11. Graddy, D. Gender and online discourse in the principles of economics. Journal of Asynchronous Learning Networks 8(4): 3-14, 2004.

12. Koory, M. Differences in learning outcomes for the online and F2F versions of an introduction to Shakespeare. Journal of Asynchronous Learning Networks 7(2): 18-34, 2003.

13. Kumari, D. Connecting graduate students to virtual guests through asynchronous discussions. Journal of Asynchronous Learning Networks 5(2): 53-63, 2001.

14. Meyer, K. Face to face versus threaded discussions: The role of time and higher order thinking. Journal of Asynchronous Learning Networks 7(3): 55-65, 2003.

15. Morse, K. Does one size fit all? Exploring asynchronous learning in a multicultural environment. Journal of Asynchronous Learning Networks 7(1): 37-56, 2003.

16. Oliver, M. and G. Shaw. Asynchronous discussion in support of medical education. Journal of Asynchronous Learning Networks 7(1): 56-67, 2003.

17. Parker, D. and A. Gemino. Inside on-line learning comparing conceptual and technique learning performance in place-based and ALN formats. Journal of Asynchronous Learning Networks 5(2): 6492, 2001.

18. Picciano, A. Beyond student perceptions: Issues of interaction, presence, and performance in an online course. Journal of Asynchronous Learning Networks 6(1): 21-40, 2002. 
19. Ross, S., A. Kukulska-Hulme, H. Chappel and H. Joyce. Taking e-moderating skills to the next level: Reflecting on the design of conferencing environments. Journal of Asynchronous Learning Networks 8(2): 115-137, 2004.

20. Shaw, G. and W. Pieter. The use of asynchronous learning networks in nutrition education: Student attitude, experiences and performance. Journal of Asynchronous Learning Networks 4(1): 40-51, 2000.

21. Spiceland, D. and C. Hawkins. The impact on learning of an asynchronous active learning course. Journal of Asynchronous Learning Networks 6(1): 68-75, 2002.

22. Vandergrift, K. The anatomy of a distance education course: A case study analysis. Journal of Asynchronous Learning Networks 6(1): 76-90, 2002.

23. Yang, H. and J. Tang. Effects of social network on students' performance: A Web-based forum study in Taiwan. Journal of Asynchronous Learning Networks 7(3): 93-107, 2003.

24. Angeli, C., N. Valanides, and C. Bonk. Communication in a Web-based conferencing system: The quality of computer-mediated interactions. British Journal of Educational Technology 34(1): 31-43, 2003.

25. Carswell, L., P. Thomas, M. Petre, B. Price and M. Richards. Distance education via the Internet: The student experience. British Journal of Educational Technology 31(1): 29-46, 2000.

26. Collings, P. and J. Pearce. Sharing designer and user perspectives of web site evaluation: A crosscampus collaborative learning experience. British Journal of Educational Technology 33(3): 267278, 2002.

27. Cunningham-Atkins, H., N. Powell, D. Moore, D. Hobbs and S. Sharpe. The role of cognitive style in educational computer conferencing. British Journal of Educational Technology 35(1): 69-80, 2004.

28. Lindblom-Ylänne, S. and H. Pihlajamäki. Can a collaborative network environment enhance essay-writing processes? British Journal of Educational Technology 34(1): 17-30, 2003.

29. Macdonald, J. and P. Twining. Assessing activity-based learning for a networked course. British Journal of Educational Technology 33(5): 603-618, 2002.

30. Murphy, E. Recognising and promoting collaboration in an online asynchronous discussion. British Journal of Educational Technology 35(4): 421-431, 2004.

31. Salmon, G. Mirror, mirror, on my screen: Exploring online reflections. British Journal of Educational Technology 33(4): 379-391, 2002.

32. Wearmouth J., A.P. Smith and J. Soler. Computer conferencing with access to a 'guest expert' in the professional development of special educational needs coordinators. British Journal of Educational Technology 35(1): 81-93, 2004.

33. Hubscher-Younger, T. and N. Narayanan. Authority and convergence in collaborative learning. Computers and Education 41(4): 313-334, 2003.

34. Johnson, S., C. Suriya, S. Won Yoon, J. Berrett and J. La Fleur. Team development and group processes of virtual learning teams. Computers and Education 39(4): 379-393, 2002.

35. Kear, K. Following the thread in computer conferences. Computers and Education 37(1): 81-99, 2001.

36. Light, P., E. Nesbitt, V. Light and S. White. Variety is the spice of life: Student use of CMC in the context of campus-based study. Computers and Education 34(3-4): 257-267, 2000.

37. MacDonald, J. Assessing online collaborative learning: Process and product. Computers and Education 40(4): 377-391, 2003.

38. Martínez, A., Y. Dimitriadis, B. Rubia, E. Gómez and P. de la Fuente. Combining qualitative evaluation and social network analysis for the study of classroom social interactions. Computers and Education 41(4): 355-368, 2003.

39. Mazzolini, M. and S. Maddison. Sage, guide or ghost? The effect of instructor intervention on student participation in online discussion forums. Computers and Education 40(3): 237-253, 2003. 
40. Tolmie, A. and J. Boyle. Factors influencing the success of computer-mediated communication (CMC) environments in university teaching: A review and a case study. Computers and Education 34(2): 119-140, 2000.

41. Wilson, E. Student characteristics and computer-mediated communication. Computers and Education 34(2): 67-76, 2000.

42. Putz, P. and P. Arnold. Communities of practice: Guidelines for the design of online seminars in higher education. Education, Communication and Information 1(2): 181-195, 2001.

43. Swan, K. Building learning communities in online courses: The importance of interaction. Education, Communication and Information 2(1): 23-49, 2002.

44. De Abreu Moreira, D. and E. Quintino Da Silva. A method to increase student interaction using student groups and peer review over the Internet. Education and Information Technologies 8(1): 4754, 2003.

45. Hawkey, K. Asynchronous text-based discussion: A case study with trainee teachers. Education and Information Technologies 8(2): 165-177, 2003.

46. Hawkey, K. Assessing online discussions working along the grain of current technology and educational culture. Education and Information Technologies 9(4): 377-386, 2004.

47. Lockhorst, D., W. Admiraal, A. Pilot and W. Veen. Design elements for a CSCL environment in a teacher training programme. Education and Information Technologies 7(4): 377-384, 2002.

48. White, B. and R. Le Cornu. Email reducing stress for student teachers. Education and Information Technologies 7(4): 351-357, 2002.

49. Chen, G., C. Wang and K. Ou. Using group communication to monitor Web-based group learning. Journal of Computer Assisted Learning 19(4): 401-415, 2003.

50. Jones, C. and M. Asensio. Experiences of assessment Using phenomenography for evaluation. Journal of Computer Assisted Learning 17(3): 306-313, 2001.

51. De Laat, M. and V. Lally. It's not so easy: Researching the complexity of emergent participant roles and awareness in asynchronous networked learning discussions. Journal of Computer Assisted Learning 20(3): 165-171, 2004.

52. Ritchie, G. and S. Peters. Using narratives in conferences to improve the CMC learning environment. Journal of Computer Assisted Learning 17(4): 376-385, 2001.

53. Thomas, M.J.W. Learning within incoherent structures: The space of online discussion forums. Journal of Computer Assisted Learning 18(3): 351-366, 2002.

54. Weller, M. Implementing a CMC tutor group for an existing distance education course. Journal of Computer Assisted Learning 16(3):178-183, 2000.

55. Åhlberg, M., A. Kaasinen, T. Kaivola and L. Houtsonen. Collaborative knowledge building to promote in-service teacher training in environmental education. Technology, Pedagogy and Education 10(3): 227-238, 2001.

56. Brett, C. Off-line factors contributing to online engagement. Technology, Pedagogy and Education 13(1): 83-95, 2004.

57. Clarke, L. Putting the ' $C$ ' in ICT: Using computer conferencing to foster a community of practice among student teachers. Technology, Pedagogy and Education 11(2): 143-162, 2002.

58. Cook, D. and J. Ralston. Sharpening the focus: Methodological issues in analyzing online conferences. Technology, Pedagogy and Education 12(3): 361-376, 2003.

59. Galanouli, D. and J. Collins. Using unmediated computer conferencing to promote reflective practice and confidence-building in initial teacher education. Technology, Pedagogy and Education 9(2): 237-254, 2000.

60. Mackinnon, G. Inter-rater reliability of an electronic discussion coding system. Technology, Pedagogy and Education 12(2): 219-230, 2003.

61. Maor, D. Teacher's and students' perspectives on on-line learning in a social constructivist learning environment. Technology, Pedagogy and Education 12(2): 201-217, 2003. 
62. Miller, D. and J. Ewing. Beyond knowledge transmission? Computer-supported learning in teacher education: Some benefits in terms of stress, control and self-belief. Technology, Pedagogy and Education 9(3): 363-376, 2000.

63. Seabrooks, J., S. Kenney and M. LaMontagne. Collaboration and virtual mentoring: Building relationships between pre-service and in-service special education teachers. Technology, Pedagogy and Education 9(2): 219-236, 2000.

64. Tsui, A. and W. Ki. Teacher participation in computer conferencing: Socio-psychological dimensions. Technology, Pedagogy and Education 11(1): 7-22, 2002.

65. Hiltz, R., N. Coppola, N. Rotter, M. Turoff and R. Benbunan-Fich. Measuring the importance of collaborative learning for the effectiveness of ALN. Journal of Asynchronous Learning Networks 4(2):103-125, 2000.

66. Vygotsky, L. Mind in Society. Cambridge, MA: Harvard University Press, 1978.

67. Laurillard, D. Rethinking University Teaching: A Framework for the Effective Use of Educational Technology. London: Routledge, 1993.

68. Johnson, D. and R. Johnson. Learning Together and Alone: Cooperative, Competitive, and Individualistic Learning. London: Prentice-Hall, 1987.

69. Lave, J. and E. Wenger. Situated Learning: Legitimate Peripheral Participation. Cambridge, UK: Cambridge University Press, 1991.

\section{ABOUT THE AUTHOR}

Dr. Michael Hammond is senior lecturer in ICT at the Institute of Education, University of Warwick. He has carried out research into online learning environments and teacher development over several years and has published widely in academic and professional journals. He has developed online learning environments for a range of courses and now has responsibility for a specialist ICT teacher training program and a professional program for practicing teachers. His research interests include teacher professional development, online discussion, and the use of web logs in higher education. 